\title{
O inglês vernacular afro-americano: descrição e implicações sociolinguísticas
}

\author{
The African American Vernacular English: \\ description and sociolinguistics implications \\ El inglés vernáculo afroamericano: \\ descripción e implicaciones sociolingüísticas
}

\author{
Alexandre Stein ${ }^{1}$ (D) https://orcid.org/0000-0002-1805-0810
}

\begin{abstract}
RESUMO: Neste estudo abordamos questões relativas ao inglês vernacular afro-americano e suas implicações sociolinguísticas. A problemática levantada aqui refere-se ao cenário encontrado em muitas salas de aulas de escolas públicas regulares daquele país, nas quais diferentes etnias com diferentes línguas são atendidas por professores que, muitas vezes, se sentem desorientados quanto à forma de abordar tal multiplicidade. Nosso foco principal é a variedade do inglês vernacular afro-americano (IVAA) ou African American Vernacular English (AAVE). Estudos desenvolvidos desde a década se 1970, sobretudo os de Labov $(1972,2008)$, são até hoje discutidos, pois a situação dos falantes do IVAA parece ainda causar divergências entre os acadêmicos que pesquisam o assunto. A grande questão aqui é como conciliar a variante do IVAA com o ensino de inglês padrão/culto preconizado em sala de aula. No Brasil, encontramos situação semelhante quando nos referimos ao tratamento dado aos falantes da variedade rural (BORTONI-RICARDO, 2011). Além dos aspectos sócio-histórico-culturais sobre o ensino-aprendizagem de inglês aos afrodescendentes norte-americanos, apresentamos também os aspectos sintáticos causadores de divergências entre o inglês padrão/culto e o inglês vernacular afro-americano. Documentos oficiais americanos como o "Bilingual Education Act" (1968) e órgãos como o "National Council of Teachers of English" (2008) estão em consonância com pesquisadores como Labov (2008) e Pullum (1999) que reafirmam a necessidade de conscientizar o professorado sobre as questões sociolinguísticas envolvidas e alertam para 0 respeito e a aceitação de variantes não-padrão em sala de aula.
\end{abstract}

PALAVRAS-CHAVE: Língua inglesa. Sociolinguística. Inglês vernacular afro-americano.

\footnotetext{
${ }^{1}$ Doutor em Estudos da Linguagem (Fonética e Fonologia da Língua Inglesa) pela Universidade Estadual de Londrina. Professor de Língua Inglesa com experiência no setor privado e no setor público. E-mail: alexandrestein02@gmail.com
} 


\begin{abstract}
The aim of this study is to address issues related to the African American Vernacular English and its sociolinguistics implications. What we problematize here is the situation found in many public schools' classrooms from the United States of America, in which teachers have to deal with different ethnic groups and with speakers of other first languages rather than English. Most of these teachers feel disorientated about how to deal with such linguistic multiplicity. Our focus is on the African American Vernacular English (AAVE) variety. Studies carried out since the 1970s, mostly the ones led by Labov (2008), are still discussed nowadays because the situation of the AAVE seem to cause divergences among the scholars who research this subject. The main issue pointed out here is how to reconcile the AAVE variant and the teaching of standard/cultured English Language in schools. In Brazil, we find a similar situation when we refer to the speakers of the rural variant and the teaching and learning of standard/cultured Portuguese (BORTONI-RICARDO, 2011). Besides the socio-historic-cultural aspects regarding the teaching and learning of English to the North American African descendants, we also present the syntactic aspects, which cause the biggest divergences between standard/cultured English and the African American Vernacular English variant. American official documents as the "Bilingual Education Act" (1968) and institutions like the "National Council of Teachers of English" (2008) are in accordance with researchers like Labov (1979-2008) and Pullum (1999) whom reaffirm the need to make teacher aware of the sociolinguistic issues involved and the need to respect and accept the non-standards variants inside the classroom.
\end{abstract}

KEYWORDS: English Language. Sociolinguistics. African American Vernacular English.

RESUMEN: El objetivo de este estudio es abordar cuestiones relacionadas con el inglés vernáculo afroamericano y sus implicaciones sociolingüísticas. El problema planteado lo encontramos en un escenario particular, las salas de aulas de muchas escuelas públicas regulares de los Estados Unidos, en donde los maestros se ven forzados a lidiar con estudiantes de diferentes grupos étnicos y cuyo idioma materno no es el inglés. La gran mayoría de los profesores se ven desorientados cuando tratan de lidiar con tal multiplicidad lingüística. En esta oportunidad, nuestro enfoque principal es la variación del inglés vernáculo afroamericano (IVAA) o African American Vernacular English (AAVE). Diferentes estudios han sido desarrollados desde la década de 1970, en su gran mayoría por Labov (1972, 2008), que aún se discuten hoy en día, ya que la situación de los hablantes de IVAA todavía parece causar divergencias entre los académicos que investigan el tema. La gran pregunta aquí es cómo conciliar la variante IVAA con la enseñanza de inglés estándar / cultural recomendada en el sala de aula. En Brasil, nos encontramos una situación similar cuando nos referimos al tratamiento dado a los hablantes que provienen de las áreas rurales (BORTONI-RICARDO, 2011). Sin embargo, además de los aspectos socio-históricos y culturales de la enseñanza y el aprendizaje del inglés para descendientes afroamericanos, también nos enfrentamos a otra gran divergencia, los aspectos sintácticos que causan divergencias entre el inglés estándar / cultural y el inglés vernáculo afroamericano. Documentos oficiales estadounidenses tales como: "Bilingual Education Act" (1968) y otros elaborados por los organismos como el "National Council of Teachers of English" (2008) están en línea con investigadores como Labov (2008) y Pullum (1999) los cuales reafirman la necesidad de sensibilizar a los docentes sobre los problemas sociolingüísticos involucrados y alertar sobre el respeto y la aceptación de variantes no-estándares en las salas de aula.

PALABRAS CLAVE: Idioma inglés. Sociolingüística. Inglés Vernáculo Afroamericano. 


\section{Introdução}

Dentre as vertentes do ensino de línguas, ensinar língua materna é, talvez, o mais desafiador tendo em vista a multiplicidade de contextos em que os professores se veem inseridos. É nesse sentido que apresentamos aqui um breve panorama dos desafios enfrentados por professores norte-americanos que ensinam língua inglesa, como língua materna, na maioria das escolas públicas em diversas partes daquele país. Neste estudo, daremos destaque às questões relacionadas ao atrito entre a coexistência do inglês padrão/culto ${ }^{2}$ e da variedade do inglês vernacular afro-americano na escola e na sociedade norte-americana.

Da mesma forma que o ensino de língua portuguesa, no Brasil, é regulado por documentos oficiais como os Parâmetros Curriculares Nacionais (PCN) e as Diretrizes Curriculares da Educação Básica (DCE), nos Estados Unidos o ensino de língua inglesa também é regulado por documentos e políticas educacionais que provêm do Departamento de Educação daquele país. Esses documentos e estas políticas públicas visam à melhoria da qualidade do ensino através da padronização de procedimentos pedagógicos, da oferta de programas de formação continuada de professores e sistemas de avaliação destes profissionais. Estas medidas também têm como objetivo melhorar os resultados dos alunos nos quesitos estipulados para as habilidades linguísticas que esses devem dominar em cada etapa da educação básica.

Ao focalizarmos a realidade dos professores norte-americanos, verificamos que estes têm uma realidade bastante desafiadora com relação ao ensino de língua materna na maioria das escolas regulares. Em 2019, dos estimados 50.8 milhões de estudantes que entraram nas escolas públicas, desde a pré-escola até o Ensino Médio, 46,65\% eram brancos, 27,36\% hispânicos, 15,16\% negros, 5,32\% asiáticos, 4,53\% de outras etnias, $0,98 \%$ indígenas $^{3}$.

Como mencionado anteriormente, focalizamos neste estudo o número de alunos de outras nacionalidades e o de estudantes afrodescendentes. Como podemos ver, aproximadamente $38,19 \%$ das crianças e jovens em idade escolar são os chamados "ELL" (English Language Learners), sigla que designa aprendizes de outras

\footnotetext{
${ }^{2}$ Embora saibamos que autores como Faraco (2008), entre outros, fazem distinção entre língua padrão e língua culta, neste artigo utilizamos o termo padrão/culto para designar a variante da língua inglesa que não sofre discriminação social, ou seja, não recebe estigma social.

${ }^{3}$ Fonte: National Center for Education Statistics. Disponível em: http://nces.ed.gov/fastfacts/display.asp?id=372. Acesso em: 9 maio 2020.
} 
nacionalidades que frequentam as escolas públicas regulares norte-americanas e precisam aprender inglês. A esse percentual de alunos de outras etnias, acrescenta-se o percentual de alunos afrodescendentes (15,16\%) o que resulta num total de 53,35\%. Essa realidade exige dos professores uma formação mais ampla que os capacite a ajudar esses alunos a aprenderem.

Segundo Samson e Collins (2012, p. 1), pesquisadores de universidades americanas têm buscado na literatura sobre ensino de Língua Inglesa como segunda língua e em medidas educacionais, subsídios para dar suporte aos professores que, na maioria dos casos, vão se deparar com salas de aula em que quase $40 \%$ de seus alunos são falantes de línguas outras maternas e 15,16\% são falantes da variedade vernacular afro-americana da Língua Inglesa. Dentre os aspectos para melhorar a eficácia do trabalho dos professores com os chamados 'ELL' (aprendizes de língua inglesa) nas áreas de "linguagem oral, linguagem acadêmica e necessidades culturais" os autores mencionados apontam a necessidade de "diretrizes específicas e consistentes" nas seguintes esferas: 1) "uma nova autorização do Ato regulador da Educação básica (nos níveis elementar e secundário), 2) "revisões ao Conselho Nacional de Normas de Credenciamento de Formação de Professores"; 3) "Regulamentações Estaduais"; 4) "Programas de Formação de Professores"; 5) "Exames de Certificação Estadual"; 6) Regulamentação da avaliação do desempenho de professores observados" e; 7) "Desenvolvimento profissional ligado à avaliação de professores" (SAMSON; COLLINS, 2012, p. 3) ${ }^{4}$.

Um dos desafios postos aos professores norte-americanos é o como lidar com as variedades da língua inglesa encontradas em sala de aula. Uma dessas, e a que também vamos dar destaque neste artigo, é a variedade inglês vernacular afroamericano (IVAA) ou Black English Vernacular (BEV), mais recentemente renomeada para African American Vernacular English (AAVE), amplamente estudada e descrita nas obras de William Labov, dentre outros. Embora os falantes desta variedade sejam, em sua maioria, cidadãos norte-americanos nativos, por influência de diversos fatores socioculturais eles se utilizam de uma linguagem considerada de menor prestígio pela sociedade e, por isso, é objeto de pesquisa neste estudo.

\footnotetext{
4 "Reauthorization of the Elementary and Secondary Education Act or ESEA; Revisions to National Council for Accreditation of Teacher Education or NCATE Standards; State regulations; Teacher-preparation programs; State certification exams; Teacher-observation rubrics in performance evaluations; Professional development linked to teacher evaluations." (SAMSON; COLLINS, 2012, p. 3).
} 
Nas seções seguintes, vamos abordar as implicações da variação linguística nas salas de aula de Língua Inglesa como língua materna nos Estados Unidos e como os estudos sociolinguísticos podem contribuir para a conciliação desse conflito entre variedades linguísticas e língua culta no contexto daquele país.

\section{0 inglês vernacular afro-americano}

Sobre a origem dessa variedade do inglês, não há um consenso entre os linguistas que a estudam, alguns dizem que ela nasceu da interação entre os negros escravizados na América do Norte com os trabalhadores das então 13 colônias da época da colonização. Outros dizem que sua estrutura é herança da variedade do inglês falado na África Ocidental (Nigéria e Gana). Outros ainda afirmam que as simplificações presentes no inglês vernacular afro-americano (IVAA ou BEV ou ebonics ${ }^{5}$ ) provêm do crioulo Caribenho, pois negros escravizados dessa região também foram trazidos para os Estados Unidos durante sua colonização (RICKFORD, [2003?]).

Uma das obras de maior repercussão sobre o IVAA é o livro "English in the inner city: studies of black English vernacular" (Inglês do gueto: estudos sobre o inglês vernacualr negro, Tradução nossa), de William Labov, publicado em 1972. No capítulo 5 dessa obra, Labov apresenta o texto The logic of non-standard English (A lógica do inglês não-padrão), no qual ele discorre sobre as justificativas que alguns estudos dão para o mal desempenho de alunos negros provenientes de áreas economicamente menos favorecidas (BERIETER et al., 1966; BERIETER; ENGELMANN, 1966; DEUTSCH et al., 1967; DEUTSCH; KATZ; JENSEN, 1968 apud LABOV, 1972).

Muitos dos pesquisadores daquela época, sobretudo os da área da psicologia educacional, sustentavam a premissa de que os rendimentos ruins dos estudantes negros das escolas dos guetos eram resultado de duas ideologias: a "ideologia do dom" e a "ideologia do déficit cultural". A primeira, parte do princípio de que tendo garantido o seu lugar na escola, o aproveitamento de cada indivíduo vai depender do "dom", isto é, da "aptidão, inteligência" e "talento" de cada um (SOARES, 2002, p. 10). A segunda, defende a hipótese de que "a condição de vida" das "classes dominantes" é que

\footnotetext{
${ }^{5}$ Ebonics significa "discurso dos negros" (uma mistura das palavras em inglês 'ebony' (negro) e 'phonics' (fônica). O termo foi criado em 1973 por um grupo de acadêmicos negros que não gostavam da conotação negativa do termo "Inglês não-padrão negro" que havia sido cunhado nos anos 1960 quando começaram os primeiros estudos linguísticos, em larga escala, sobre a fala das comunidades afro-americanas" (RICKFORD, [2003?]).
} 
proporcionaria às crianças, pertencentes à essa classe, "formas de socialização [...] desde a primeira infância" que Ihes permitissem "o desenvolvimento [...] de características, hábitos, atitudes, conhecimentos, habilidades, interesses" e Ihe dariam "a possibilidade de sucesso na escola" (SOARES, 2002, p. 13).

Ou seja, como descrito por Labov (1972, p. 201) considerava-se que "as crianças negras das áreas de gueto" tinham "sua capacidade de expressão verbal comprometida" porque "recebiam pouco estímulo verbal" e "ouviam muito pouca linguagem bem-formada". Segundo essa teoria "elas não eram capazes de produzir sentenças completas, não sabiam o nome de objetos comuns e não conseguiam formar conceitos ou expressar pensamentos lógicos" (LABOV, 1972, p. 201) devido às deficiências de exposição aos sons da língua inglesa culta e à cultura.

Labov (1972, p. 201) refuta essa teoria e afirma que a noção de "privação verbal" era parte do mito disseminado pela psicologia educacional que se espalhou de forma viral naquela época. Ele ainda sugere que o que os linguistas podem fazer para amenizar os efeitos de tal disseminação é esclarecer as relações entre o dialeto padrão e os não-padrão, com base na teoria sociolinguística.

Com o intuito de situar (e não justificar) as asserções feitas pela psicologia educacional daquela época, é importante ressaltar o contexto sócio-histórico-cultural que os Estados Unidos viviam nos anos de 1960 e 1970. Essa era uma época de forte segregação racial na qual havia uma tendência de perpetuar a ideia de que era possível provar, cientificamente, a inferioridade genética, cultural e intelectual dos negros.

Em seus estudos, Labov não descarta as estatísticas que demonstravam a performance inferior dos alunos negros provenientes de áreas pobres, sobretudo na leitura. Afirmando que a sociedade americana daquela época (e porque não dizer da atualidade) se utiliza essencialmente de um sistema de distinção de cor, mais do que de um sistema de distinção econômica, o autor então postula um questionamento que vai orientar suas pesquisas sociolinguísticas: "Por qual mecanismo as "barras de cores" podem impedir crianças de aprender a ler?" (LABOV, 1972, p. 204). ${ }^{8}$

\footnotetext{
${ }^{6}[\ldots]$ They cannot speak complete sentences. do not know the names of common objects, cannot form concepts or convey logical thoughts (LABOV, 1972, p. 201).

7 O termo "color bar" (barras de cor) refere-se a um sistema social e legal no qual pessoas de raças diferentes são separadas e não têm os mesmos direitos e oportunidades. (cf. http://dictionary.cambridge.org/dictionary/english/colour-bar)

8 "By what mechanism does the color bar prevent children from learning to read?" (LABOV, 1972, p. 204).
} 
Como apresentado anteriormente, estudos daquela época realizados com crianças negras apresentam resultados que as consideram verbalmente incapazes ou como falantes deficientes da língua inglesa (BERIETER et al., 1966; BERIETER; ENGELMANN, 1966; DEUTSCH et al., 1967; DEUTSCH; KATZ; JENSEN, 1968 apud LABOV, 1972). Em seu texto, William Labov (1972) desqualifica esses estudos, pois segundo ele, a coleta de dados feita em laboratórios e nas escolas causava um efeito de bloqueio nos informantes que agiam de forma defensiva e monossilábica quando interagiam com o pesquisador. $\mathrm{O}$ autor afirma que, em nenhum momento, as análises se baseavam em interações entre as crianças e seus pais, familiares ou amigos no ambiente de suas casas, por exemplo.

Coletas de dados, conduzidas por Labov (1972) e sua equipe, demonstraram que mudanças na atitude do entrevistador podem resultar em consideráveis mudanças de atitude dos entrevistados, especialmente quando colocados num ambiente menos formal. Tanto a interação quanto a produção linguística de crianças negras melhoraram consideravelmente quando interagiam com outras crianças enquanto eram entrevistadas e quando se abordavam assuntos menos artificiais e mais relevantes, como racismo, bullying etc.

Para o autor, a relação assimétrica entre professores/pesquisadores e as crianças negras são o grande motivo pelo qual obtiveram-se resultados como os apresentados nos estudos anteriormente descritos. Para ele:

Isto significa que a situação social é o determinante mais poderoso do comportamento verbal e que um adulto deve estabelecer uma relação social de forma adequada com uma criança, se ele quiser descobrir o que ela sabe fazer. $E$ isso, é o que muitos professores não sabem fazer (LABOV, 1972, p. 212).

Acreditamos que conclusões como essa devam ter um reflexo direto na sociolinguística educacional, pois reconhece as relações de poder impostas por alguns professores no ensino de línguas, sejam elas estrangeiras ou maternas, e evidencia a falta de preparo de alguns professores para lidar com as variedades linguísticas existentes.

\footnotetext{
9 "It means that the social situation is the most powerful determinant of verbal behavior and that an adult must enter into the right social relation with a child if he wants to find out what a child can do. This is just what many teachers cannot do" (LABOV, 1972, p. 212).
} 
Avançando alguns anos no tempo, encontramos um fato que reavivou a discussão em torno da questão do IVAA. Em 1996, numa reunião do conselho escolar do Estado da Califórnia nos Estados Unidos foi anunciado que a variedade vernacular afro-americana do inglês deveria ser reconhecida como uma língua nova, diferente do inglês padrão, e que merecia a atenção das políticas públicas educacionais e do professorado. Essa decisão foi tomada pensando no contexto da cidade de Oakland, uma cidadezinha pobre ao leste da baía de São Francisco, onde a metade da população era afrodescendente.

Esse anúncio, embora bem-intencionado, pois visava a adoção de uma "pedagogia culturalmente sensível"10, teve grande repercussão negativa, com jornais e revistas como "The New York Times" e "The Economist" rechaçando esse pronunciamento e, até mesmo, fazendo piadas de mal gosto com a palavra "Ebonics" (como já mencionado, outro termo designado para referir-se a variedade do inglês falado pelos afro-americanos). (PULLUM, 1999).

No artigo intitulado "African American vernacular English is not standard English with mistakes", Geoffrey K. Pullum (1999) afirma que para muitos americanos, o IVAA é apenas um inglês falado com muitas gírias especiais e erros gramaticais. No entanto, ele demonstra que o inglês falado pelos afrodescendentes americanos não é apenas um inglês padrão falado com erros. Para Pullum (1999, p. 41), quando indivíduos falantes de uma mesma língua cometem desvios, como por exemplo, referir-se a mesma coisa com nomes diferentes, muitas pessoas veem isso como um 'erro'. Em suas palavras, "há uma forte tendência de aceitar-se uma como a forma correta de falar e a outra como incorreta", especialmente quando uma das duas variedades tem um maior prestígio social.

Segundo esse autor, o grande equívoco que aquele conselho escolar do estado da Califórnia cometeu foi insistir na premissa de que o inglês vernacular afro-americano era uma língua à parte, uma outra língua diferente do inglês padrão. Na verdade, o IVAA é sim bastante diferente do inglês padrão/culto, mas não pode ser considerado uma outra língua, é apenas um dialeto, uma variedade.

Para tecer essa conclusão, Pullum se baseia no fato de que:

\footnotetext{
${ }^{10}$ Do original "culturally responsive pedagogy". Termo cunhado por Frederick Erickson (1987 apud BORTONIRICARDO, 2005, p. 128). Tal pedagogia tem como objetivo "criar em sala de aula ambientes de aprendizagem onde se desenvolvam padrões de participação social, modos de falar e rotinas comunicativas presentes na cultura dos alunos".
} 
[...] todas as palavras usadas no IVAA podem ser claramente identificadas no inglês padrão, e a maior parte da gramática do IVAA é a mesma da variedade padrão. As pequenas partes que não o são, são equiparadas a outros dialetos do inglês que nunca são confundidas com outras línguas (PULLUM, 1999, p. 44-45). ${ }^{11}$

Com essa afirmação, o autor reafirma que "o IVAA, como um dialeto do inglês padrão, merece respeito e aceitação" (PULLUM, 1999, p. 45) ${ }^{12}$. Como um respeitado linguista, ele cumpre o seu papel de tentar desfazer o mal-entendido de 1996 e esclarecer o que difere uma língua de outra e o que deve ser considerado como dialetos de uma mesma língua.

Na seção seguinte, apontaremos quais são as diferenças mais marcantes entre o inglês padrão e o inglês vernacular afro-americano.

\section{IVAA $x$ inglês padrão/culto}

Muitos afirmam que o IVAA é incorreto por apresentar, sobretudo na fala, inúmeras divergências linguísticas do inglês padrão/culto como: o apagamento do verbo de ligação to be (ser, estar), a dupla negação, etc. No entanto, autores como Pullum (1999) contestam essa premissa e apresentam evidências de que afirmações generalizadas são sempre perigosas. Apresentamos aqui, alguns desses aspectos contrastando-os com o inglês padrão/culto.

\section{0 uso do verbo to be}

Para muitos estudiosos, ou mesmo leigos, que tenham contato com o IVAA, a primeira impressão que se tem é que nesse dialeto o verbo to be (ser, estar) não é usado como no inglês padrão/culto. Ou seja, parece haver um apagamento dessa estrutura quando se analisa enunciados de um falante dessa variedade. Aparentemente esse apagamento parece ser usado de forma indiscriminada. Porém, segundo Pullum (1999), o não uso do verbo to be não é tão aleatório assim.

Para esse pesquisador, há alguns casos em que o to be não é apagado, como por exemplo quando o mesmo é enfatizado (tônico) por estar no final de sentenças. O Quadro 1, a seguir, apresenta alguns exemplos do explicitado anteriormente.

\footnotetext{
${ }^{11}[\ldots]$ all the words used in AAVE can be clearly identified in Standard English too, and most of AAVE grammar is the same as that of Standard English. The bits that are not are mostly paralleled in certain other dialects of English that are never mistaken for other languages (PULLUM, 1999, p. 44-45).

${ }_{12}^{1}[\ldots]$ AAVE as a dialect of English still deserves respect and acceptance (PULLUM, 1999, p. 45).
} 
Quadro 1 - Exemplos de não apagamento do verbo to be

\begin{tabular}{|l|l|l|}
\hline \multicolumn{1}{|c|}{ IVAA } & \multicolumn{1}{c|}{ Tradução } & \multicolumn{1}{c|}{ Inglês padrão/culto } \\
\hline There already is one. & Já existe um. & There is already one. \\
\hline $\begin{array}{l}\text { Couldn't nobody say what color } \\
\text { he is. }\end{array}$ & $\begin{array}{l}\text { Ninguém conseguia dizer qual } \\
\text { era a cor dele. }\end{array}$ & $\begin{array}{l}\text { Nobody could say what color he } \\
\text { is. }\end{array}$ \\
\hline
\end{tabular}

Fonte: o próprio autor com base em Pullum (1999).

Outro caso em que o verbo to be nunca é apagado na variedade IVAA é quando ele está na forma negativa, no entanto, usa-se uma expressão não formal, ou seja, ou invés de am not, isn't (is not) ou aren't (are not) os falantes de IVAA usam ain't. Por exemplo, You ain't goin' to no heaven (Você não vai para o céu. No inglês padrão/culto: You aren't going to heaven) ou I ain't no fool (Eu não sou tolo. No inglês padrão/culto: I'm not a fool).

Segundo Pullum (1999), o verbo to be também não é apagado se ele for usado nos casos apresentados no Quadro 2 a seguir:

Quadro 2 - Casos em que o verbo to be não é apagado no IVAA

\begin{tabular}{|l|l|l|}
\hline \multicolumn{1}{|c|}{ Casos } & \multicolumn{1}{|c|}{ IVAA } & \multicolumn{1}{c|}{ Inglês padrão/culto } \\
\hline $\begin{array}{l}\text { Num presente perfeito } \\
\text { remoto: }\end{array}$ & $\begin{array}{l}\text { She been married. } \\
\text { (Ela tem estado casada.) }\end{array}$ & She has been married. \\
\hline Na forma infinitiva: & $\begin{array}{l}\text { You got to be strong. } \\
\text { (Você tem que ser forte). }\end{array}$ & You've got to be strong. \\
\hline Em frases imperativas: & Be careful! (Tenha cuidado) & Idem \\
\hline Ao expressar um hábito: & $\begin{array}{l}\text { He be singn. } \\
\text { (Ele está cantando) (com o } \\
\text { significado de: Ele geralmente, } \\
\text { habitualmente canta). }\end{array}$ & He is singing. \\
\hline $\begin{array}{l}\text { Na primeira pessoa do } \\
\text { singular: }\end{array}$ & I am all right (Eu estou bem). & Idem \\
\hline No passado: & I was cool(Eu fui legal). & Idem \\
\hline Em interrogativas: & Is that you? (É você?). & Idem \\
\hline Em "question tags": & $\begin{array}{l}\text { I don't think you are ready, are } \\
\text { you? }\end{array}$ & Idem \\
\hline
\end{tabular}

Fonte: o próprio autor como base em Pullum (1999).

O referido autor, afirma veementemente que qualquer "afirmação generalizada de que os falantes de IVAA sempre omitem o verbo to be" deve ser considerada "falsa" (PULLUM, 1999, p. 47).

\section{A dupla negação}

Para Pullum (1999, p. 48), o caso da dupla negação não deve ser considerado um desvio da língua inglesa padrão/culta, mas sim, visto como uma "marcação múltipla" de negação num mesmo enunciado. Ele sustenta essa afirmação dizendo que frases do 
inglês padrão/culto como I'm not an ugly fellow (Eu não sou um cara feio) e I haven't ever seen anything like it (Eu nunca vi nada como isso) se traduzem no IVAA em I ain't no ugly dude (dupla negação) e I ain't never seen nothing like it (tripla negação).

Os críticos do IVAA contestam essa visão, pois segundo a lógica, duas negações criariam uma positiva. Então, em He didn't see nothing (Ele não viu nada), significa que ele viu alguma coisa, tornando, portanto, a frase ilógica. Mas, para Pullum (1999, p. 48), "não há qualquer similaridade entre esse sistema lógico mecânico e a gramática de uma língua natural"13 até porque em $I$ ain't never seen nothing like it há três marcações de negação (ain't, never, nothing) e não apenas duas. Ele cita o caso da negação dupla em outras línguas como no Italiano, no Espanhol e no Russo e conclui argumentando que "a gramática da negação não é a mesma para todas as línguas"14.

Se pensarmos o português do Brasil, observaremos que seus falantes, mesmo os que dominam a norma culta, também usam a dupla negativa e nem por isso são estigmatizados. Como por exemplo: "Eu não tinha nada"; "Eu não fiz nada"; Ele não é ninguém"; etc.

Será, então, que a descriminação ao IVAA tem algo que transcende a estigmatização linguística? Por que alguns linguistas parecem querer culpar os falantes dessa variedade como os únicos que estão corrompendo a língua inglesa? Na seção seguinte veremos como Labov (2008) aborda essa questão.

\section{A sociolinguística de William Labov e o IVAA}

Na obra "Padrões Sociolinguístico" de William Labov, cuja primeira publicação data de 1972, o autor tece considerações sobre a variação linguística nos Estados Unidos em seus diversos aspectos: morfológico, sintático, estilístico e fonético-fonológico. Segundo o autor, as variações linguísticas, sobre tudo o IVAA, são motivadas por diferentes fatores como o social, o étnico e a própria evolução da língua. Ele ainda argumenta que muitos linguistas tendem a explicar a variação linguística existente, em geral, como proveniente de dois fenômenos: a alternância de código (code-switiching) e a variação livre. A primeira, refere-se a uma 'mistura dialetal' realizada por usuários de uma língua como língua estrangeira ou segunda língua. Já a segunda, tem a ver com as escolhas lexicais,

\footnotetext{
${ }^{13}$ But there is little similarity between this mechanical logical system and the grammar of any natural language (PULLUM, 1999, p. 48).

${ }^{14}[. .$.$] that the grammar of negation is not the same in all languages (PULLUM, 1999, p. 48).$
} 
morfossintáticas e fonológicas que o usuário de uma língua faz quando fala. No entanto, Labov (2008) afirma que não é tão simples assim.

Ao analisar uma breve passagem, transcrita a seguir, em que um garoto negro americano de 12 anos explica o jogo de 'skelly'15, Labov levanta diversos questionamentos com relação aos fenômenos, como a variação livre ou estilística, comumente usados pelos linguistas para justificar a utilização dessa variante.

Quadro 3 - Transcrição da fala de um garoto negro americano explicando o jogo de 'skelly'

$A n^{\prime}$ den like IF YOU MISS ONESIES, de othuh person shoot to skelly; ef he miss, den you go again. An' IF YOU GET IN, YOU SHOOT TO TWOSIES. An' IF YOU GET IN TOWSIES, YOU GO TO tthreesies. An' IF YOU MISS tthreesies, THEN THE PERSON tha' miss skelly shoot THE SKELLIES an' shoot in THE ONESIES: an' IF HE MISS, YOU GO f'om tthreesies to foursies.
Então se você perde primeiro, a outra pessoa atira skelly; se ela perde, então você vai novamente. $E$ se você ganha, você vai pela segunda vez. E se você ganha pela segunda vez, você vai para a terceira. E se você perde na terceira vez, então a pessoa que perdeu atira o skelly e volta a ser o primeiro. E se ela perde, você vai para a terceira ou quarta vez.

Fonte: Labov (2008, p. 221-222).

$\mathrm{Na}$ transcrição acima, onde as maiúsculas representam o falar afro-americano e as minúsculas o inglês padrão, Labov (2008) questiona se as escolhas feitas pelo informante devem mesmo ser tratadas como 'variação livre' ou 'variação estilística', já que se tem consciência de que são formas estigmatizadas (ex. 'de' ao invés de 'the'). E se olharmos pelo ângulo da alternância, como justificar a motivação para se alternar 18 vezes em uma passagem relativamente curta?

Labov (2008) ainda complementa afirmando que essa falta de clareza talvez seja o maior motivo pelo qual os linguistas tendem a focar em análises que privilegiam a língua em si e não o seu uso em comunidades de fala ${ }^{16}$. Para alguns linguistas, essa questão se resolveria com a apresentação dos conceitos de dialeto ${ }^{17}$ ou idioleto ${ }^{18}$, mas mais uma vez Labov refuta esses conceitos como justificativa para o uso das formas menos privilegiadas da linguagem.

Numa outra obra de Labov (1972, p. 213), "The logic of non-standard English", já citada neste estudo, o autor levanta vários questionamentos sobre a real necessidade de se "impor", na escola, "o estilo verbal da classe média às crianças de outros grupos

\footnotetext{
15 'Skelly' é um antigo jogo de rua da cidade de Nova York que se assemelha ao jogo de amarelinha.

16 Segundo Cristófaro-Silva (2014, p. 12) "Uma comunidade de fala consiste de um grupo de falantes que compartilham de um conjunto específico de princípios subjacentes ao comportamento linguístico.

17 Dialeto: variedade linguística que se distingue em relação a outras variedades linguísticas que tenham propriedades gramaticais, lexicais ou social diferentes. Pode-se referir, por exemplo, ao dialeto mineiro ou a um dialeto feminino. (CRISTÓFARO-SILVA, 2011, p. 91).

${ }^{18}$ Idioleto: caracteriza-se pelas particularidades da fala de um indivíduo. (CRISTÓFARO-SILVA, 2014).
} 
culturais". Uma de suas perguntas centrais é se a "sintaxe complicada" e a "elaboração vazia" da linguagem usada pelos alunos do Ensino Médio e das faculdades americanas, não seria apenas um estilo elaborado ao invés de um "código ou sistema superior".

Embora Labov reconheça a utilidade das crianças provenientes dos chamados 'guetos' adquirirem habilidades verbais consideradas de domínio da classe média como "a precisão na ortografia", "a habilidade de explicar os significados das palavras" e o domínio "das palavras de origem latina"19", argumentando em favor do uso de uma linguagem simplificada, ele afirma que pessoas da classe trabalhadora e, em sua maioria falantes do IVAA são, muitas vezes, "narradores, pensadores e debatedores muito mais eficazes do que os falantes da classe média que temporizam, qualificam e perdem seus argumentos no meio a uma enorme quantidade de detalhes irrelevantes" (LABOV, 1972, p. 214).

Apesar dessa afirmação de Labov (1972) ser passível de contestação, quem nunca passou por situações em que não se expressou de forma eficaz por estar procurando as palavras adequadas e relutando para não cometer nenhum desvio linguístico com relação à norma culta?

No embate entre a 'verbosidade' e a 'precisão', o autor expõe que seus argumentos servem para desmistificar as ideias, disseminadas por psicólogos educacionais, de que os falantes do IVAA são incapazes de elaborarem discursos sobre assuntos "abstratos", "logicamente complexos" ou responder às "questões hipotéticas". Ele ainda afirma que o conceito de agramaticalidade não se aplica as sentenças formadas por falantes dessa variedade. Para Labov:

Nossos próprios estudos (Labov, 1966) sobre a gramaticalidade da fala cotidiana mostram que a grande maioria dos discursos em todos os contextos são formados por sentenças completas e o restante pode ser reduzido a formas gramaticais por meio de um pequeno conjunto de regras de edição. [...] O difuso mito de que a maior parte dos discursos são agramaticais, é sem dúvida baseado em gravações feitas em conferências cultas onde se obtém um grande número de sequências agramaticais irreduzíveis (LABOV, 1972, p. 222). ${ }^{20}$

\footnotetext{
${ }^{19}$ As palavras de origem latina (latinate words) que fazem parte da língua inglesa têm, em geral, um prestígio maior do que as de origem anglo-saxão e são consideradas como de maior dificuldade para os falantes nativos de língua inglesa.

${ }^{20}$ Our own studies (LABOV, 1966) of the grammaticality of everyday speech show that the great majority of utterances in all contexts are complete sentences, and most of the rest can be reduced to grammatical form by a small set of editing rules. [...] The widespread myth that most speech is ungrammatical is no doubt based upon tapes made at learned conferences, where we obtain the maximum number of irreducibly ungrammatical sequences. (LABOV, 1972, p. 222).
} 
Ou seja, para ele, a maioria das sentenças agramaticais são frequentemente produzidas em meios ditos cultos e não o contrário. Portanto, devemos rever o conceito de agramaticalidade da linguagem produzida por falantes de outras variantes de uma língua que não a culta, como é o caso dos falantes do inglês vernacular afro-americano entre outros.

\section{Considerações Finais}

Desde 1968, com atos legislativos legais como o "Bilingual Education Act" os Estados Unidos têm tentado estabelecer políticas educacionais que englobem os desafios enfrentados pelos $E L L$ e os falantes de variedades linguísticas não padrão (a exemplo do IVAA) e têm alocado recursos para dar suporte a esses aprendizes. Esse país tem também desenvolvido pesquisas com o intuito de desfazer alguns mitos com relação ao ensino/aprendizagem destes alunos.

Ao estimular os professores a terem contato com pesquisas sociolinguísticas que investigam e descrevem estas questões, os Estados Unidos têm amenizado os impactos produzidos pela realidade multicultural, étnica e social encontrada nas escolas. Longe de se obter uma resposta definitiva para o tratamento das questões sobre variações linguísticas na escola, vê-se que tem havido uma maior preocupação/cuidado com tais aspectos na atualidade.

As dificuldades em sanar questões relacionadas ao ensino e a aprendizagem da língua padrão/culta nas escolas públicas dos Estados Unidos revelam a complexidade da referida questão não só naquele país, mas em outros, como o Brasil, que também apresenta essas dificuldades. Ao nosso ver, o papel da escola é ensinar a norma padrão/culta, pois as demais variedades os alunos já dominam. Porém, como se ver, o impasse em convencer os alunos da importância de dominar a norma padrão/culta persiste. O mais importante talvez seja conscientizar professores e alunos de que as variedades de menor prestígio, como o falar rural e, no caso dos EUA, o IVVA, têm seu valor e devem ser respeitadas. Acreditamos que o que se deve ser destacado neste contexto é que um falante é considerado fluente em uma língua quando ele/ela é capaz de transitar pelas variedades da língua de acordo com o contexto social em que o falante se encontra. 
Algumas medidas educacionais que podem auxiliar alunos e professores nessa área tão controversa são: 1) a apresentação aos alunos de conteúdos curriculares desafiadores; 2) a determinação de altas expectativas com relação aos alunos falantes de variedades linguísticas diferentes da variedade padrão/culta; 3) o uso de tecnologias com a finalidade de melhorar a interação e o desenvolvimento das habilidades de escrita e edição textual destes alunos; 4) o estímulo aos professores para reconhecerem o 'background' cultural desses aprendizes, e assim, utilizarem uma metalinguagem mais adequada; 5) a utilização da alternância de código linguístico e; 6) a negociação da disparidade entre as práticas de letramento domésticas e escolares, ou seja, uma tentativa de diminuir a distância cultural entre a escola e a casa destes alunos (NCTE, 2008).

Como se vê, não se pode dizer que estas medidas vão solucionar todos os problemas encontrados pelos professores norte-americanos em suas salas de aula, mas devemos acreditar que a melhor maneira de abordar tais questões é através da conscientização de todos os atores envolvidos, sobre as multiplicidades linguísticas encontradas num país que, muitas vezes, toma como certo ser monolíngue.

\section{Referências}

BORTONI-RICARDO, Stella Maris. Do campo para a cidade: estudo sociolinguístico de migração e redes sociais. Tradução de Stella Maris Bortoni-Ricardo, Maria do Rosário Rocha Caxangá. São Paulo: Parábola Editorial, 2011.

BORTONI-RICARDO, Stella Maris. Nós chegemo na escola e agora? Sociolinguística e educação. São Paulo: Parábola, 2005.

CRISTÓFARO-SILVA, Thais. Fonética e fonologia do português. roteiro de estudos e guia de exercícios. 10. ed. São Paulo: Contexto, 2014.

LABOV, William. Padrões sociolinguísticos. Tradução de Marcos Bagno, Maria Marta Pereira Scherre e Caroline Rodrigues Cardoso. São Paulo: Parábola Editorial, 2008.

LABOV, William. The logic of non-standard English. In: LABOV, William. English in the inner city. studies of black English vernacular. Philadelphia, PA: University of Pennsylvania Press, 1972.

NATIONAL COUNCIL OF TEACHERS OF ENGLISH - NCTE. English language learners. a policy research brief. 2008. Disponível em: http://www.ncte.org. Acesso em: 23 mar. 2019. 
PULLUM, Geoffrey K. African American vernacular English is not standard English with mistakes. In: WHEELER, Rebecca S. (ed.). The workings of language: from prescriptions to perspectives. Westport, CT: Praeger, 1999, p. 39-58.

RICKFORD, John R. What is ebonics? (African American Vernacular English). Washington, DC: The Linguistic Society of America, [2003?]. Disponível em: http://www.linguisticsociety.org/content/what-ebonics-african-american-english. Acesso em: 23 mar. 2019.

SAMSON, Jennifer F.; COLLINS, Brian A. Preparing all teachers to meet the needs of English language learners. applying research to policy and practice for teacher effectiveness. Washington, DC: Center for American Progress, 2012. Disponível em: www.americanprogress.org. Acesso em: 23 mar. 2019.

SOARES, Magda. O fracasso da/na escola. In: SOARES, Magda. Linguagem e escola: uma perspectiva social. 17. ed. São Paulo: Ática, 2002. p. 8-17. 